\title{
Outcomes of Patients with Multiple Myeloma in Middle Euphrates Region of Iraq: Data from Developing Country
}

\author{
Ahmed Mjali', Safaa Ayad Jawad', Nareen Tawfeeq Abbas²
}

${ }^{1}$ Department of Hematology /Oncology, Al- Hussein Medical City, Karbala, Iraq. ${ }^{2}$ Department of Hematology, Hiwa Hematology/ Oncology Hospital, Sulaymaniyah, Iraq.

\begin{abstract}
Background: Multiple myeloma (MM) is a B cells neoplasm characterized by plasma cells clonal proliferation. Aims: The aim of this study was to evaluate incidence, prevalence and pattern of multiple myeloma (MM) in Middle Euphrates region of Iraq. Materials and Methods: A retrospective descriptive conducted at Al-Hussein center in Karbala province of Iraq between February 2012 and February 2020. Results: A total of 78 patients with MM were included in this study, median age at presentation was 59.8 years, M:F ratio was $0.85: 1$. The most frequent presenting complain was bony lesions in $87.18 \%$ of patients, IgG was the most frequent paraprotient in $61.53 \%$ and VRD was the most common used protocol in $37.18 \%$. Survival rate was higher in younger \& female patients, while there was no correlation between myeloma defining events and early death in our study. Conclusion: MM presenting age in our region was close to other parts of Iraq and neighboring countries but younger than western countries with female predominance. Giving that the majority of the patients presented with advance stage disease, therefore raising awareness of early symptoms is recommended for early diagnosis and proper management.
\end{abstract}

Keywords: Multiple myeloma- Middle Euphrates Region- Iraq

Asian Pac J Cancer Biol, 6 (2), 99-103

\section{Introduction}

Multiple myeloma (MM) is a malignant hematological disease characterized by the irregular proliferation of clonal plasma cells in the bone marrow [1]. These clonal plasma cells secrete large quantities of monoclonal immunoglobulin into the serum and/or urine, leading to significant morbidity due to end-organ destruction [2].

The etiology of MM is unclear but it commonly occur among farmers, wood workers, leather workers, petroleum products exposed workers and occupations associated with radiation. Several studies suggested that various etiological factors may have played a role in MM etiology such as viral infections, inflammatory disorders, autoimmune diseases, allergic diseases \& family history [3-4].

Early recognition of clinical symptoms is an important factor for early management and preventing irreversible complications. Several criteria have been used to diagnose MM \& distinguish it from other plasma cell diseases [5].
Submission Date: 12/18/2020Ａcceptance Date: 03/24/2021

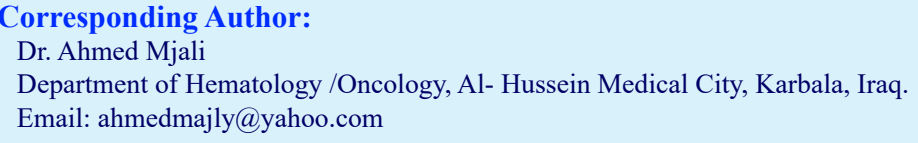

The following criteria must be fulfilled:

A. Clonal bone marrow plasma cells $\geq 10 \%$ or biopsy-proven bony or extramedullary plasmacytoma

B. Any one or more of the following myeloma- defining events:

1. Hypercalcemia: Serum calcium $>0.25 \mathrm{mmol} / \mathrm{L}$ ( $>1 \mathrm{mg} / \mathrm{dL}$ ) higher than the upper limit of normal or $>2.75$ $\mathrm{mmol} / \mathrm{L}(>11 \mathrm{mg} / \mathrm{dL})$.

2. Renal insufficiency: Creatinine clearance $<40 \mathrm{~mL} /$ min or serum creatinine $>177 \mathrm{mmol} / \mathrm{L}(>2 \mathrm{mg} / \mathrm{dL})$.

3. Anemia: Hemoglobin value $<10 \mathrm{~g} / \mathrm{dL}$ or hemoglobin $>2 \mathrm{~g} / \mathrm{dL}$ below the lowest limits of normal hemoglobin levels.

4. Bone lesions: One or more osteolytic lesions on skeletal radiography, CT or PET/CT.

5. Clonal bone marrow plasma cell $\geq 60 \%$.

6. Involved: uninvolved serum free light chain (FLC) ratio $\geq 100$ and the involved FLC level must be $10 \mathrm{mg}$ / 
dL or higher.

7. More than one focal lesion on MRI studies $(\geq 5 \mathrm{~mm}$ in size) [6].

Until 2000, the mainstays of MM therapy were alkylating agents, corticosteroids and high-dose chemotherapy with autologous stem cell transplantation (ASCT). Recently, thalidomide, bortezomib, lenalidomide, carfilzomib and pomalidomide are emerged as effective agents that dramatically improved clinical outcomes [7].

This was the first statistical study of MM in Middle Euphrates region of Iraq, it can help provide basic information, assess progress in recent years and develop future myeloma treatment strategies in this area of our county.

\section{Materials and Methods}

This was a retrospective, descriptive study conducted in Al-Hussein cancer center in Karbala province of Iraq on MM patients diagnosed between February 2012 to February 2020. This center was established in November 2011 with oncology \& hematology wards. It covers not only Karbala population but other patients from Middle Euphrates region of Iraq who are referred to this center for solid \& hematological malignancies treatment [8-9]. All patients had full blood \& biochemistry profile especially complete blood count, renal functions tests, serum and urine electrophoresis, serum calcium, skeletal survey and bone marrow aspirate with biopsy. Data also provide information about sex, age, occupational history and treatment plan. Patients with inconclusive results were excluded from the study. The study protocol was approved by Ethical Committee of Teaching Hospital in Karbala, Iraq.

The statistical package for social sciences (SPSS) for windows, version 24 was used for entering, managing and analysis of data. Findings were presented in Tables and figures using MS-office software version 2013. P-values of 0.05 or less were regarded as statistically significant.

\section{Results}

Seventy eight patients were enrolled in the study. Median age at presentation was 59.8 years ( range 33-91 years). Thirty six patients $(46.15 \%)$ were males and 42 (53.85\%) were females with M:F ratio 0.85:1.

Regarding myeloma-defining events, bony lesions presented in 68 patients $(87.18 \%)$ followed by anemia in 58 patients $(74.36 \%)$, renal impairment in 19 patients $(24.36 \%)$ and hypercalcemia in 14 patients $(17.95 \%)$.

The most common treatment protocol in our center was VRD protocol in 29 patients $(37.18 \%)$ followed by VD protocol in 21 patients $(26.92 \%)$, VCD protocol in 12 patients $(15.38 \%)$, VTP protocol in 9 patients $(11.54 \%)$, melphalan \& prednisolone in 4 patients $(5.13 \%)$, supportive treatment in 2 patients $(2.57 \%)$ and VAD protocol in one patient $(1.28 \%)$ as shown in (Table 1$)$.

The paraprotein types of MM patients showed that the most common type was $\operatorname{IgG}$ in 48 patients $(61.53 \%)$ followed by IgA in 15 patients (19.24\%). Regarding
Table 1. Baseline Characteristics of MM Patients in Middle Euphrates Region of Iraq (N=78)

\begin{tabular}{lc}
\hline Characteristics & $\mathrm{N}(\%)$ \\
\hline Age in years & 59.8 \\
$\quad$ Median & $33-91$ \\
Range & \\
Gender & $36(46.15)$ \\
$\quad$ Male & $42(53.85)$ \\
Female & \\
Myeloma-defining events & $58(74.36)$ \\
Anemia & $68(87.18)$ \\
Bony lesions & $14(17.95)$ \\
Hypercalcemia & $19(24.36)$ \\
Renal impairment & \\
Treatment protocols & $29(37.18)$ \\
VRD & $21(26.92)$ \\
VD & $12(15.38)$ \\
VCD & $9(11.54)$ \\
VTP & $4(5.13)$ \\
Melphalan \& prednisolone & $1(1.28)$ \\
VAD & $2(2.57)$ \\
Supportive & VD,
\end{tabular}

VRD, bortezomib; lenalidomide; dexamethasone; VD, bortezomib; dexamethasone; VTP, bortezomib; thalidomide; prednisone; VCD, bortezomib, cyclophosphamide, dexamethasone; VAD, vincristine; doxorubicin; dexamethasone.

Immunofixation, 45 patients $(57.70 \%)$ had kappa chain, $29(37.17 \%)$ had lambda chain and $4(5.13 \%)$ were non secretary as shown in Figure 1.

The mean duration of follow-up was 24.67 months. A total of 16 patients $(20.51 \%)$ died during the study period as shown in Figures 2 and 3. Survival rate was higher in patients $<50$ years $83.33 \%$ versus $66.67 \%$ in patients $>70$ years and among females $(83.33 \%$ versus $75.00 \%$ in males), and these differences were statistically significant $(\mathrm{P}$ value $=0.013$ and 0.031 , respectively) . On the other hand, there was no correlation between myeloma defining events and treatment protocols on survival ( $\mathrm{P}$ value $>0.05$ each) (Table 2 ).

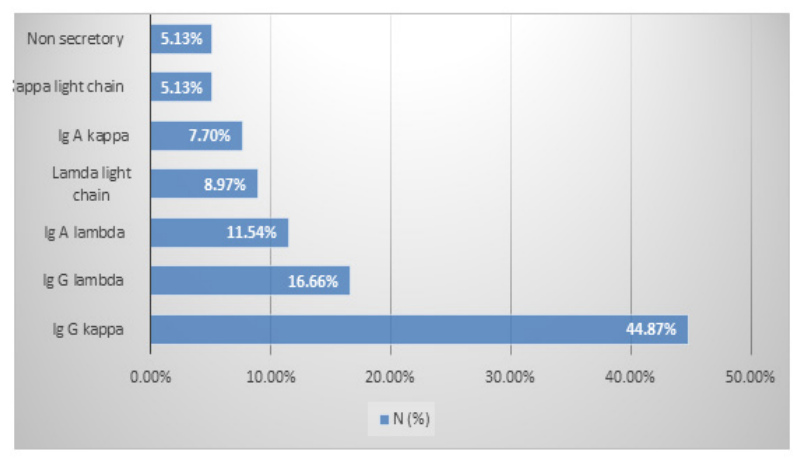

Figure 1. Types of Paraproteins 


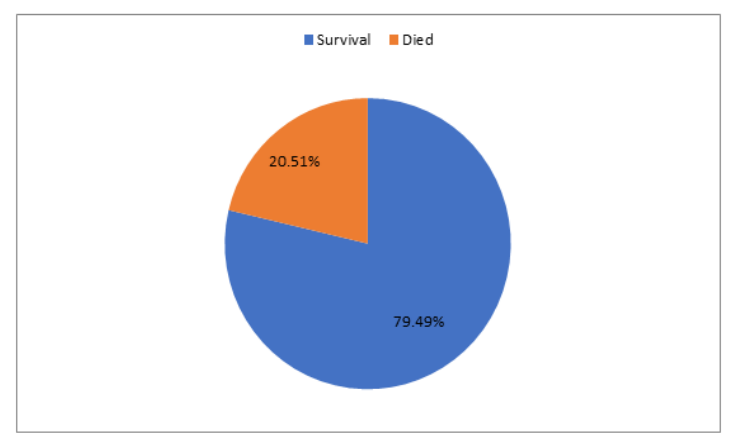

Figure 2. Survival and Death Rates

\section{Discussion}

MM accounts for about $1 \%$ of all cancers and approximately $10 \%$ of all hematologic malignancies. More than 30,000 new cases are diagnosed in the US per year and more than 12,000 patients have died from the disease, while in Iraq MM accounts for around $1.08 \%$ of

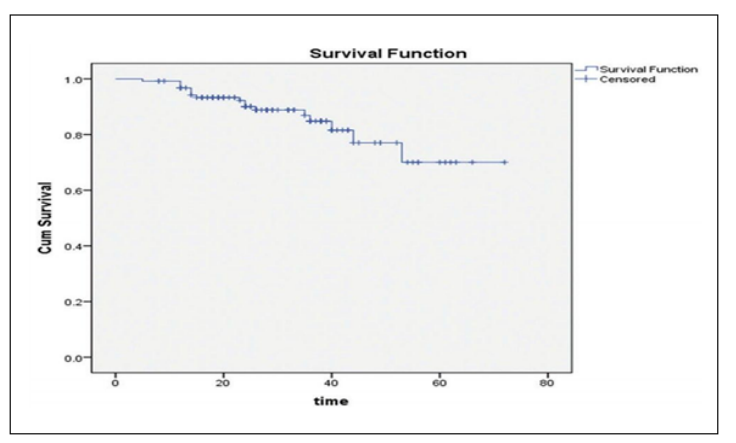

Figure 3. Mean Survival Time

cancer patients [10-11]. It is generally more common in men \& among African-Americans and median age of patients was around 65 years [12].

In the present study, the median age at presentation was 59.8 years which was close to median age in other parts of Iraq, India, China and Turkey [12-15]. While mean age in US was a decade older than ours[16]. Interestingly, in

Table 2. Survival Rate Based on the Clinical Characteristics and Treatment Protocols

\begin{tabular}{|c|c|c|c|}
\hline \multirow[t]{2}{*}{ Characteristic } & \multirow{2}{*}{$\begin{array}{l}\text { N (62) } \\
\text { Survive }\end{array}$} & \multirow{2}{*}{$\begin{array}{c}\text { N (16) } \\
\text { Died }\end{array}$} & \multirow[t]{2}{*}{$P$ value } \\
\hline & & & \\
\hline \multicolumn{4}{|l|}{ Age in years } \\
\hline$<50$ & $10(83.33 \%)$ & $2(16.67 \%)$ & $0.013^{*}$ \\
\hline $50-59$ & $22(81.48 \%)$ & $5(18.52 \%)$ & \\
\hline $60-69$ & $20(83.33 \%)$ & $4(16.67 \%)$ & \\
\hline$\geq 70$ & $10(66.67 \%)$ & $5(33.33 \%)$ & \\
\hline \multicolumn{4}{|l|}{ Gender } \\
\hline Male & $27(75.00 \%)$ & $9(25.00 \%)$ & $0.031 *$ \\
\hline Female & $35(83.33 \%)$ & $7(16.67 \%)$ & \\
\hline \multicolumn{4}{|l|}{ Myeloma-defining events } \\
\hline Anemia & & & 0.249 \\
\hline Yes & $44(75.86 \%)$ & $14(24.14 \%)$ & \\
\hline No & $18(90.00 \%)$ & $2(10.00 \%)$ & \\
\hline Bony lesions & & & 0.435 \\
\hline Yes & $54(79.41 \%)$ & $14(20.59 \%)$ & \\
\hline No & $8(80.00 \%)$ & $2(20.00 \%)$ & \\
\hline Hypercalcemia & & & 0.381 \\
\hline Yes & $11(78.57 \%)$ & $3(21.43 \%)$ & \\
\hline No & $51(79.69 \%)$ & $13(20.31 \%)$ & \\
\hline Renal impairment & & & 0.27 \\
\hline Yes & $17(89.47 \%)$ & $2(10.53 \%)$ & \\
\hline No & $45(76.27 \%)$ & $14(23.73 \%)$ & \\
\hline \multicolumn{4}{|l|}{ Treatment protocols } \\
\hline VD & $18(85.71 \%)$ & $3(14.29 \%)$ & 0.143 \\
\hline VTP & $3(33.33 \%)$ & $6(66.67 \%)$ & \\
\hline VRD & $29(100.00 \%)$ & $0(0.00 \%)$ & \\
\hline Melphalan \& prednisolone & $2(50.00 \%)$ & $2(50.00 \%)$ & \\
\hline $\mathrm{VCD}$ & $9(75.00 \%)$ & $3(25.00 \%)$ & \\
\hline VAD & $1(100 \%)$ & $0(0.00 \%)$ & \\
\hline Supportive & $0(0.00 \%)$ & $2(100 \%)$ & \\
\hline
\end{tabular}

* significant differences $(\mathrm{P} \leq 0.05)$; VD, bortezomib, dexamethasone; VTP, bortezomib, thalidomide, prednisone ;VRD, bortezomib, lenalidomide and dexamethasone; VCD, bortezomib, cyclophosphamide, dexamethasone; VAD, vincristine, doxorubicin, dexamethasone. 
our center MM was more common in females than males, that was inconsistent with previous studies conducted in north Iraq, Turkey,China and US [12,14,16,17].

Clinical presentations can be highly varied among patients, in our region bony lesions were the most common myeloma-defining event, same results in India, Iran and Turkey while in Africa \& US anemia was the most common one $[14,16,18-20]$. The most frequent monoclonal protein in our patients was $\mathrm{IgG}$, which was consistent with previous studies in north Iraq, US, China and Turkey [12,14,16,17,21].

During the past decade, the survival rate of MM patients was significantly increased. But the median overall survival was less than five years [22]. In the present study, overall survival rate was high $79.49 \%$, this may be explained by short follow-up period and a small sample size. Survival rate was greater in young patients, same results were obtained from a study conducted at 17 institutions from North America, Europe and Japan where younger myeloma patients were more favorable features and showed better survival [23]. On the other hand, in our study survival was better in female, same results were obtained from a study done by Derman et al., but disagreed with previously published data suggesting no difference in survival outcomes by sex [24-25].

There was no correlation between myeloma defining events and survival in our patients, which was inconsistent with previous studies conducted in China, Japan, Greece and Africa where survival rate was decreased in patients with myeloma defining events [12, 26-28].

Cancer patients tend to present with heterogonous presentations and complications making treatment of those patients as a major concern. Detection of the disease in its early stages before the appearance of signs \& symptoms can significantly improve outcomes [29-35]. Treatment of MM is a great challenge to the health system with different treatment protocols. The advent of thalidomide, lenalidomide, and bortezomib changed the standard of treatment and improved the survival of MM patients [36]. In our center VRD protocol (bortezomib, lenalidomide and dexamethasone) was the commonly used regimen. This protocol became as standard of care in many centers with successful results [37]. In the present study, survival rate improved in patients used VRD protocol compared to other protocols, but this result was statistically not significant.

In conclusion, the results of this study showed that Iraqi patients with multiple myeloma were younger than patients in western countries. Most of patients presented with bony lesions in the late stages. IgG was the most frequent paraprotein in the patients. VRD protocol was the most commonly used protocol with good outcomes. Survival rate was higher in younger \& female patients, while there was no correlation between myeloma defining events and early death in our study. Future studies in other parts of Iraq with a larger sample size \& longer follow up period are recommended to understand MM pattern in our war- torn country.

\section{References}

1. Alant J, Pool R, Thomson J, et al. The Diagnosis and Investigation of Multiple Myeloma in 2018. Arch Clin Pathol J. 1:1. of. 2018; 6:2.

2. Kazandjian D. Multiple myeloma epidemiology and survival: A unique malignancy. Seminars in Oncology. 2016 Dec;43(6):676-681. https://doi.org/10.1053/j. seminoncol.2016.11.004

3. Gupta M, Pal R, Tikoo D. Multiple myeloma: the disease and its treatment. Int J Basic. Clin Pharmacol. 2013 Mar.2(0):103-21.

4. Alexander DD, Mink PJ, Adami H, Cole P, Mandel JS, Oken MM, Trichopoulos D. Multiple myeloma: A review of the epidemiologic literature. International Journal of Cancer. 2007;120(S12):40-61. https://doi.org/10.1002/ijc.22718

5. Mikhael J, Ismaila N, Cheung MC, Costello C, Dhodapkar MV, Kumar S, et al. Treatment of Multiple Myeloma: ASCO and CCO Joint Clinical Practice Guideline. Journal of Clinical Oncology. 201905 10;37(14):1228-1263. https:// doi.org/10.1200/jco.18.02096

6. Gandolfi S, Prada CP, Richardson PG. How I treat the young patient with multiple myeloma. Blood. 201809 13;132(11):1114-1124. https://doi.org/10.1182/ blood-2017-05-693606

7. Rajkumar SV, Kumar S. Multiple Myeloma: Diagnosis and Treatment. Mayo Clinic Proceedings. 2016 01;91(1):101119. https://doi.org/10.1016/j.mayocp.2015.11.007

8. Mjali A, Jawad SA, Al Baroodi BNH. Gynecological Cancer in Middle Euphrates Region of Iraq , 2012-2020. Asian Pacific Journal of Environment and Cancer. 2020 06 04;3(1):17-18. https://doi.org/10.31557/apjec.2020.3.1.17-18

9. Mjali A, Abbas S. Imatinib Mesylate Adherence in Chronic Myeloid Leukemia Patients: Data from Middle Euphrates Region of Iraq. Sys Rev Pharm. 2021 Jan;12(1):83-7.

10. Rajkumar SV. Multiple myeloma: 2018 update on diagnosis, risk-stratification, and management. American Journal of Hematology. 2018 08;93(8):1091-1110. https://doi. org/10.1002/ajh.25117

11. Mjali A, Najeh Hasan Al Baroodi B. Some Facts About Cancers in Karbala province of Iraq, 2012-2020. Asian Pacific Journal of Cancer Care. 202006 07;5(2):67-69. https://doi.org/10.31557/apjcc.2020.5.2.67-69

12. Lu J, Lu J, Chen W, Huo Y, Huang X, Hou J. Clinical features and treatment outcome in newly diagnosed Chinese patients with multiple myeloma: results of a multicenter analysis. Blood Cancer Journal. 2014 08;4(8):e239-e239. https://doi. org/10.1038/bcj.2014.55

13. Kumar L, Vikram P, Kochupillai V. Recent advances in the management of multiple myeloma. Natl Med J India. 2006 Jan 1;19(2):80.

14. Ozkalemkas F, Ali R, Tunali A, et al. Multiple myeloma in the region of Bursa, Turkey: a retrospective analysis. J Environ Pathol Toxicol Oncol. 1996 Jan 1;15(2-4):267-70.

15. Moreau P, Attal M, Facon T. Frontline therapy of multiple myeloma. Blood. 201505 14;125(20):3076-3084. https:// doi.org/10.1182/blood-2014-09-568915

16. Kyle RA, Gertz MA, Witzig TE, Lust JA, Lacy MQ, Dispenzieri A, Fonseca R, Rajkumar SV, Offord JR, Larson DR, Plevak ME, Therneau TM, Greipp PR. Review of 1027 Patients With Newly Diagnosed Multiple Myeloma. Mayo Clinic Proceedings. 2003 01;78(1):21-33. https://doi. org/10.4065/78.1.21

17. Abbas N, Sheikha A, Mjali A. Clinical Outcomes of Patients with Plasma Cell Neoplasm in Sulaymaniyah Province of Iraq. Sys Rev Pharm. 2020;11(6):1142-4. 
18. Eslick R, Talaulikar D. Multiple myeloma: from diagnosis to treatment. Aust Fam Physician. 2013 Oct;42(10):684.

19. Madu A, Ocheni S, Nwagha T, Ibegbulam O, Anike U. Multiple myeloma in Nigeria: An insight to the clinical, laboratory features, and outcomes. Nigerian Journal of Clinical Practice. 2014;17(2):212. https://doi. org/10.4103/1119-3077.127561

20. Diwan A, Gandhi S, Krishna K, Shinde V. Clinical profile of the spectrum of multiple myeloma in a teaching hospital. Medical Journal of Dr. D.Y. Patil University. 2014;7(2):185. https://doi.org/10.4103/0975-2870.126335

21. Yassin A. Clinical and Laboratory Profiles of 109 Patients diagnosed as Multiple Myeloma in Erbil City. J R Fac Med Iraq. $2013 \mathrm{Jul}$ 1;55(2):121-4.

22. João C, Costa C, Coelho I, Vergueiro MJ, Ferreira M, Silva MG. Long-term survival in multiple myeloma. Clinical Case Reports. 201405 28;2(5):173-179. https://doi.org/10.1002/ ccr3.76

23. Ludwig H, Durie BGM, Bolejack V, Turesson I, Kyle RA, Blade J, et al. Myeloma in patients younger than age 50 years presents with more favorable features and shows better survival: an analysis of 10549 patients from the International Myeloma Working Group. Blood. 200804 15;111(8):4039-4047.

24. Derman BA, Langerman SS, Maric M, Jakubowiak A, Zhang W, Chiu BC. Sex differences in outcomes in multiple myeloma. British Journal of Haematology. 2020 Nov 20;192(3). https://doi.org/10.1111/bjh.17237

25. Bird SA, Cairns D, Davies FE, Boyd K, Cook G, Drayson MT, et al. Sex Differences in Multiple Myeloma Biology and Clinical Outcomes: Results from 3894 Patients in the Myeloma XI Trial. Blood. 2019 Nov 13;134(Supplement_1):4374-4374. https://doi.org/10.1182/ blood-2019-128041

26. Nakaya A, Fujita S, Satake A, Nakanishi T, Azuma Y, Tsubokura Y, Hotta M, Yoshimura H, Ishii K, Ito T, Nomura S. Impact of CRAB symptoms in survival of patients with symptomatic myeloma in novel agent era. Hematology Reports. 201702 23;9(1). https://doi. org/10.4081/hr.2017.6887

27. Eleutherakis-Papaiakovou V, Bamias A, Gika D, Simeonidis A, Pouli A, Anagnostopoulos A, Michali E, Economopoulos T, Zervas K, Dimopoulos on behalf of the Greek M MA. Renal failure in multiple myeloma: Incidence, correlations, and prognostic significance. Leukemia \& Lymphoma. 2007 01;48(2):337-341. https:// doi.org/10.1080/10428190601126602

28. Acquah ME, Hsing AW, McGuire V, Wang S, Birmann B, Dei-Adomakoh Y. Presentation and survival of multiple myeloma patients in Ghana: a review of 9 cases. Ghana Medical Journal. 201903 10;53(1):52. https://doi. org/10.4314/gmj.v53i1.8

29. Mjali A, Kareem Y, Al-Shammari H, et al. Chronic myeloid leukemia patient with isolated central nervous system blast crisis. World J Pharm Pharm Sci. 2019;8(9):111-7.

30. Mjali A, Hasan D, Al-Anssari M, et al. Myeloid sarcoma as the presenting symptom of chronic myeloid leukemia chronic phase: A case report. World J Pharm Res. 2017;6(13):10-5.

31. Mjali A, Kehiosh H, Al-Ansari M, et al. Primary Cutaneous Aspergillosis in Acute Myeloid Leukemia Patient: A Case Report. World J Pharm Res. 2017;6(15):105-11.

32. Mjali A, Al Baroodi B, Al-Shammari H, et al. Skin Reaction at Site of Intrathecal Methotrexate. World J Pharm Res. 2019;8(10):170-3.

33. Mjali A, Abbas S, Mutlag J, et al. Acute Promyelocytic Leukemia in Third Trimester Pregnant Women Treated with All-Trans-Retinoic Acid. World J Pharm Pharm Sci. 2019;8(9):146-51.

34. Mjali A, Al-Anssari M, Al-Shammari H. Vincristine Induced Vocal Cord Paralysis in Patient with Diffuse Large B-cell Lymphoma: A Case Report. World J Pharm Res. 2017;6(12):11-5.

35. Mjali A, Alshami M, Metib N, et al. Proliferating Trichilemmal Tumor: Case Report. Karbala J Med. 2017;10(2):2800-3

36. Chou T. Multiple Myeloma : Recent Progress in Diagnosis and Treatment. Journal of Clinical and Experimental Hematopathology. 2012;52(3):149-159. https://doi. org/10.3960/jslrt.52.149

37. Rosiñol L, OriolA, Rios R, SuredaA, Blanchard MJ, Hernández MT, et al. Bortezomib, lenalidomide, and dexamethasone as induction therapy prior to autologous transplant in multiple myeloma. Blood. 201909 04;134(16):1337-1345. https:// doi.org/10.1182/blood.2019000241

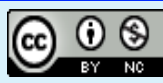

This work is licensed under a Creative Commons AttributionNon Commercial 4.0 International License. 